19/1/04

file:\fertility $\backslash$ capital mobility, ageing and opt saving.doc

\title{
Population ageing, capital mobility and optimal saving.
}

Ross S. Guest

Griffith University

Correspondence:

Professor Ross Guest

Graduate School of Management

Griffith University,

PMB 50

Gold Coast Mail Centre

Queensland,

Australia, 9726

Email: r.guest@griffith.edu.au 


\title{
Population ageing, capital mobility and optimal saving.
}

\begin{abstract}
This paper reports simulations of the effect of population ageing - in particular, lower fertility - on optimal saving and consumption under three assumptions about capital mobility: zero, perfect and imperfect. The case of imperfect capital mobility is modeled by expressing the interest rate as a function of the level of foreign liabilities. There are two policy implications emerging from the simulation results. First, there is a case for policies to provide a modest boost to the national saving rate for countries that face imminent population ageing; and the size of the increase will tend to be larger for countries with higher capital mobility. Second, the results do not present a case for policies to boost the fertility rate in countries facing falling fertility rates. Lower fertility confers a consumption dividend which implies an increase in social welfare for a range of social discount rates.
\end{abstract}

JEL: D9, E2, J0

Keywords: Demographic economics, saving, consumption. 


\section{Introduction}

Most OECD countries, and China, face imminent declines in their employment to population ratios as their populations age due to declining fertility and increased longevity. Japan, China and Europe face the sharpest declines over the next two decades, with North America and Oceania not far behind. This has led to calls for policies to boost the fertility rate and to increase the national saving rate, through higher taxes for example. The aim of this paper is to shed light on the appropriateness of such policies, given alternative assumptions about capital mobility.

The degree of capital mobility facing a country can have a bearing on the optimal response of policy-makers to population ageing. Elmendorf and Sheiner (2000) compare the effect of population ageing on optimal saving for the cases of the closed economy (zero capital mobility) and small open economy (perfect capital mobility). They show that, while optimal saving does increase for the small open economy, the optimal response of saving in the closed economy is less clear cut. The reason is that the slower growth of the labour force lowers the marginal product of capital which implies a lower return to saving. They show that whether optimal saving rises or falls in response to ageing, in the closed economy, depends on the intertemporal elasticity of substitution which determines the degree to which society is willing to shift the burden of ageing between generations.

The small open economy model might be regarded as an appropriate framework in which to consider the impact of population ageing for Australia (for example Guest and McDonald, 2001, 2002). In such a model the economy borrows and lends at a constant world interest rate which implies that capital is perfectly mobile. There is, 
however, extensive evidence that capital is not perfectly mobile internationally and is indeed quite immobile even for small open economies. For a discussion of the various explanations see Gordon and Bovenberg (1996); and for a survey of the evidence on the Feldstein-Horioka puzzle as an indicator of imperfect capital mobility see Coakley, Kulasi and Smith (1998). The most important explanation according to Gordon and Bovenberg (1996) is asymmetric information between investors of different countries. In particular, foreign investors know less about the economic prospects of another country than do the residents of that country. The result is that the equilibrium interest rate in capital importing countries is higher than the interest rate in capital exporting countries. Another reason for doubting the constant world interest rate assumption is the evidence of a risk premium in the interest rate paid by small capital importing countries, where the premium depends on their level of foreign debt. For Australia, see Juttner and Luedecke (1991).

The degree of capital immobility could be important in determining the effect of a demographic shock on optimal saving. With a constant world interest rate and a constant rate of time preference the rate of return to saving, following a demographic shock, is unaffected by the path of debt. This is not the case, however, if the interest rate is affected by the level of foreign debt for example. In that case the marginal cost of borrowing increases as debt increases and falls as debt falls. Hence the rate of return to saving is a function of the path of debt and is therefore endogenous as it is in the closed economy case. The extent to which the assumption about capital mobility matters for the path of optimal saving is an empirical question which this paper seeks to address by adopting a simulation approach. Two population ageing shocks, representing different fertility rates, 
are simulated for three capital mobility assumptions - zero, perfect and imperfect capital mobility. For the case of imperfect capital mobility we draw on the model in Glenn (1997) who considers the impact of a rise in the price of an imported production input for an economy facing an interest rate that depends on its level of foreign liabilities.

\section{The analytical framework}

Following the approach in the seminal study by Cutler et al. (1990) and later in Elmendorf and Sheiner (2000) we adopt a Ramsey-Cass-Koopmans model modified to allow for heterogeneous consumers and workers. A central planner maximises an intertemporal time-additive social welfare function of general form: ${ }^{1}$

$V=\int_{t=1}^{\infty} N_{t} \frac{c_{t}^{1-\beta}}{1-\beta} e^{-\theta t} d t$

Output is produced according to a Cobb-Douglas production function with constant returns to scale:

$$
f(k)=k^{\gamma}
$$

The variables and parameters are defined as follows:

$L=$ number of equivalent workers, weighted for productivity by age

$N=$ population

$P=$ number of equivalent consumers, weighted for consumption by age

$C=$ aggregate consumption

$D=$ aggregate foreign liabilities, nominated here as debt

$K$ = aggregate capital stock

$r=$ rate of interest

$\theta=$ rate of time preference

$\delta=$ rate of depreciation

$g=$ rate of Harrod-neutral technical progress or labour productivity growth

$l=$ employment growth

$n=$ population growth

\footnotetext{
${ }^{1}$ If $\beta=1$, (1) becomes $\left.V=\int_{t=1}^{\infty} N_{t} \ln (C / P)\right)^{-\theta t}$
} 
$p=$ growth of population, where population is measured in consumption units

$\alpha=$ support ratio $=L / P$

$\gamma=$ capital elasticity of output

$\beta=$ the planner's degree of aversion to variability between time periods. ${ }^{2}$

$\mathrm{c}=$ consumption per equivalent consumer per efficiency unit

$\mathrm{k}$ = capital stock per equivalent worker per efficiency unit

$\mathrm{d}=$ foreign liabilities per equivalent worker per efficiency unit

Define efficiency units per capita as

$E_{t}^{l}=E_{0}^{l} e^{(l+g) t} \quad$ for equivalent workers,

$E_{t}^{p}=E_{0}^{p} e^{(p+g) t} \quad$ for equivalent consumers ,

Therefore, capital stock and debt in efficiency units per equivalent worker is $k=\frac{K_{t}}{E_{t}^{l}}$ and

$d=\frac{D_{t}}{E_{t}^{l}}$, respectively. Consumption in efficiency units per equivalent consumer is

$c=\frac{C_{t}}{E_{t}^{p}}$

The number of equivalent consumers, $\mathrm{P}$, is the head count population weighted by the consumption demands of each age group. The number of equivalent workers is the head count labour force weighted by the productivity weights of each age group which are determined by relative wages for the age and gender groups. For details on the calculation of consumption weights and productivity weights see Guest and McDonald (2001). The unweighted series for the population and labour force for the base case demographic projection are obtained from the ABS (2000) and those for the low fertility scenario are calculated by Rebecca Kippen and Peter McDonald from the ANU. The base

\footnotetext{
2 If, alternatively, (1) is viewed as the discounted integral of the instantaneous utility of a representative agent, the parameter $\beta$ represents the reciprocal of the elasticity of intertemporal substitution in consumption.
} 
case assumes a total fertility rate of 1.75 , annual net immigration $=0.54 \%$ of population and an increase in life expectancy of 0.4 years every 5 years. The low fertility scenario varies this by assuming a total fertility rate of 1.75 in 1999 falling by 0.045 per year to 1.3 by 2009, at which rate fertility remains for the rest of the projection period.

Cutler et al. (1990) acknowledge that "it is not obvious how best to model [demographic change] as a single shock” (p.23). The approach they and others (e.g. Elmendorf and Sheiner, 2000) adopt is to assume that the population has been stable at which point a demographic shock occurs so that employment and population follow the projections described above. The demographic shock is unanticipated in the sense that it has not been incorporated into behaviour. It seems reasonable to argue that demographic change that is expected to occur decades into the future has not been fully or perhaps even partially incorporated into the behaviour of firms, consumers and the public sector. We follow the approach of the above authors and assume that at the beginning of the year 2000 the population is stable with employment and population by age group growing at $1.2 \%$ per annum. At that point an unanticipated demographic shock occurs and the paths of employment and population jump on to the paths that have been projected for Australia under two fertility rates: 1.75 and 1.3, as applied in Guest and McDonald, 2002. These projections assume that the age-specific employment to population ratios remain constant from the year 2000 onwards. The demographic structure is assumed to have reached a new steady state after 100 years, that is, at 2100 .

An important issue in models such as this concerns the impact of lower fertility on labour productivity growth. This could quite easily go either way, as discussed by Cutler 
et al. (1990, p. 38). On the one hand slower population growth makes innovation less profitable by reducing the gains from economies of scale through the spreading of fixed costs; and a smaller youth share of the population may reduce innovation through a loss of “dynamism”. Also, in endogenous growth models of the type in Steinman et al. (1998) lower population growth results in less human capital accumulation and therefore a lower growth rate of labour productivity. On the other hand slower labour force growth implies a higher relative price of labour and therefore greater incentive to innovate through capital investment. Also, diseconomies of higher population growth, through congestion for example, can reduce labour productivity growth.

The empirical evidence on the effect of fertility on labour productivity is relatively scarce. Galor et al. (1997), using panel data on 73 countries, find evidence that countries with smaller average family size attain higher labour productivity. They attribute this to the extra resources that parents with smaller families can provide to each of their children to finance their education. Similarly, Ahituv (2001), using panel data on 114 countries, concludes that lower population growth increases GDP per capita growth. The principal mechanism here seems to be the effect of the time required for child rearing on the labour input of their parents. Fewer children imply less time input from parents thereby freeing up labour time. ${ }^{3}$ On the other hand Hondroyiannis and Papapetrou (1999) find no long run relationship between the fertility rate and the output growth rate using time series data for the U.S. On the basis of this ambiguity in theory and evidence, Guest and McDonald (2002) assume that lower fertility has no net effect on labour productivity. That assumption is maintained in this paper.

\footnotetext{
${ }^{3}$ Properly measured, this would not amount to an effect on labour productivity but rather a change in labour input.
} 


\section{Zero capital mobility (the closed economy case).}

In the closed economy, the central planner maximizes (1) given (2) and subject to the capital accumulation equation: ${ }^{4}$

$\dot{k}=f(k)-\frac{c}{\alpha}-(l+g+\delta) k$

The optimal path for consumption satisfies :

$\frac{\dot{c}}{c}=\frac{1}{\beta}\left(f^{\prime}(k)-\delta-\theta+(\beta-1)(n-p)\right)-g$

To find the initial steady state values, set (3) and (4) equal to zero and note that in the steady state $n=p$. Setting (3) equal to zero gives

$c=\alpha[f(k)-(l+g+\delta) k]$

We set initial $k$ by assuming $K / Y=2.5$ which was equal to the actual value for the Australian economy in 2000. This gives $k=3.70$ and $c=1.198$. We set $g$, the rate of labour productivity growth equal to $1.43 \%$, in line with earlier work in Guest and McDonald (2001). This is approximately the average rate of post-war labour productivity growth in Australia. In order to ensure an initial steady state, we set (4) equal to zero and solve for $\theta$, yielding

$\theta=f^{\prime}(k)-\delta-\beta g$

which equals 5.6\%, given other parameter values: $\delta=5 \%, \gamma=0.3$ and $\beta=1$ (these are the base case values adopted in Elemendorf and Sheiner, 2000, to be discussed below).

\footnotetext{
${ }^{4}$ See Cutler (1990). The transversality condition, which states that if the terminal capital stock is positive the marginal utility of terminal consumption must be zero, is also satisfied.
} 
The transition path to the new steady state is plotted in Figure 1 for base fertility and low fertility. Optimal consumption declines monotonically, after a small initial jump, along its path to the new steady state under both base and low fertility scenarios. The new steady state level of consumption is lower as a result of the net of three effects: the dependency effect, the "Solow" effect, and the capital intensity effect (Elmendorf and Sheiner, 2000, p.63). These are discussed in Section 6.

The path to this lower level of consumption is determined by the path of the capital-labour ratio, which in turn influences the marginal product of capital and hence the return to saving. This effect is explained as follows. Capital intensity rises which increases income (in per effective worker terms). The rising capital intensity lowers the return to saving, causing consumption to decline. The rise in income and fall in consumption implies rising saving. As the excess capital is worked off the temporary increase in saving is reversed and the saving rate falls. In the low fertility case there is, for an initial period, a fall in the capital stock before it begins to rise. This is due to the initial jump in consumption being higher under low fertility, which is sufficient to reduce the capital stock. The initial jump in consumption is a residual determined by the final steady state level of consumption, from (5) given the new steady state values, and the growth rate of consumption, from (4).

The two key points about the consumption and saving paths are that, firstly, a population ageing shock leads to a temporary increase in saving and ultimately lower consumption. Secondly, lower fertility implies higher consumption than under base fertility for an initial period that lasts, in this simulation, until 2057. The reason is that in the low fertility case youth dependency is initially lower, and hence the employment to 
population ratio higher, than under base fertility. This allows an initial jump in consumption in the low fertility case (which is big enough to cause the capital stock to fall for an initial period).

\section{The open economy}

Following Glenn (1997) we adopt an open economy model with adjustment costs in investment and an interest rate that is an increasing function of the level of foreign debt. The optimization problem is to maximize (1) subject to ${ }^{5}$

$\dot{d}=(r(d)-l-g) d+\frac{c}{\alpha}+J(i)-f(k)$

and

$\dot{k}=i-(l+g+\delta) k$

where $J(i)$ is the units of output required to increase the capital stock by i units. Hence $J(i)-i$ represents the adjustment costs in terms of output required to transform goods into output. In the simulations we adopt an adjustment cost function of the form:

$$
J(i)=i\left(1+0.5 \mu \frac{i}{k}\right)
$$

and a simple linear function for $r(d)$ :

$$
r=\bar{r}+\lambda d
$$

The case of perfect capital mobility is specified by setting $\lambda=0$. Three variables: investment, consumption and debt are determined simultaneously. Debt is determined by (7); consumption is determined by

\footnotetext{
${ }^{5}$ In Glenn (1997), $f(k)$ in (1) is defined as the value added by domestic production after the purchase of an intermediate input good, since her purpose was to analyse the response to an increase in the price of an
} 
$\frac{\dot{c}}{c}=\frac{1}{\beta}\left(\frac{\partial r(d)}{\partial d} d+r(d)-\theta+n-p\right)-g$

Investment is determined by ${ }^{6}$

$\dot{q}=(r(d)+\delta) q-\left(f^{\prime}(k)+\frac{(q-1)^{2}}{2 \mu}\right)$

where

$\frac{i}{k}=\frac{q-1}{\mu}$

and $\mathrm{q}$ is the shadow price of capital.

The steady state implies that $\dot{d}=0, \dot{q}=0, \dot{c}=0$ and $\dot{k}=0$ which yields, respectively, the following steady state equations:

$$
\begin{aligned}
& c=\alpha(f(k)-J(i)-(r(d)-l-g) d) \\
& f^{\prime}(k)+\frac{(q-1)^{2}}{2 \mu}=(r(d)+\delta) q \\
& \theta=r(d)-\beta g
\end{aligned}
$$

and, by substituting (8) into (13),

$q=1+\mu(l+g+\delta)$

The value of $\mu$ is found by substituting (17) into (15). This gives $\mu=3.0$. Initial debt to GDP is set equal to $60 \%$ and the initial real interest rate is set at $6 \%$.

$\underline{4.1}$ Perfect capital mobility $(\lambda=0)$ - the small open economy case.

imported intermediate good. In the model here there are no intermediate goods. The no-ponzi game condition in which the level of debt does not grow as fast as the interest rate is also assumed to hold. ${ }^{6}$ See Barro and Salai-Martin (1994, p.123). 
This is the same as the small open economy case in Elmendorf and Sheiner (2000). They compared the effect of a single population ageing scenario on optimal consumption for the two extreme cases of the closed and small open economies.

The transition path of consumption in this case is more straightforward because the intertemporal terms of trade do not change during the consumption path. They are held constant by the constant interest rate. Hence most of the adjustment to consumption occurs with an initial drop. Indeed, without adjusting for the difference between natural and weighted persons, reflected in the term $n-p$ in (11), all of the adjustment to consumption would be in the initial drop, as in the model in Elmendorf and Sheiner (2000). In that case annual consumption is simply the constant annuity value of discounted future cash flows. Wealth or assets, defined as capital less foreign liabilities, rise in the open economy counterpart to the capital intensity effect in the closed economy.

The transition path is illustrated in Figure 2 for both base and low fertility. The large initial drop in consumption implies a large rise in optimal saving. Consumption falls by less under low fertility and remains above that under base fertility. This reflects the net gain in discounted cash flows from the dependency effect, lower capital widening requirements, and the effect of higher asset intensity on income. A decomposition of these three effects are calculated in Section 5 , for the case where $\lambda>0$

\subsection{Imperfect capital mobility (ICM) (i.e. $\lambda>0$ ).}

For the base case simulation $\lambda=0.02$ and $\bar{r}=4.8 \%$. This implies for example that if Australia's debt ratio increased from 60\% to $100 \%$ of GDP the interest rate would increase from $6 \%$ to $6.8 \%$. Simulations showed that small values of $\lambda$ were sufficient to 
yield a quite different adjustment path to that for the small open economy model (see Figure 4).

The marginal cost of capital is now augmented by a term that captures the effect of an additional dollar of borrowing on the interest rate payable on existing debt. Hence the marginal cost of capital is

$r(d)+\frac{\partial r(d)}{\partial d} d=r(d)+\lambda d$.

Figure 3 illustrates the transition path following an ageing shock from an initial steady state to the new steady state under the two fertility scenarios. A comparison with Figures 1 and 2 reveals a transition path for the ICM case that is closer to that for the closed economy case than for the small open economy, even with a smaller value of $\lambda$ (see Figure 4). Like the closed economy case the fall in consumption and rise in saving that occurs for the initial period is smaller than for the small open economy. But the subsequent fall in consumption and saving is larger. The reason is that the endogeneity of the return to saving in both the closed economy and ICM cases dampens the rise in saving and hence reduces the temporary accumulation of assets during that period, requiring a bigger drop in final consumption. The endogeneity of the return to saving occurs through the effect of changes in debt on the interest rate, whereas in the closed economy the endogeneity occurs through the effect of changes in the capital stock on the marginal product of capital.

Figures 4 and 5 illustrate the effect of different degrees of capital immobility on the optimal paths. Figure 4 reveals that the increase in steady state wealth is larger the smaller the value of $\lambda$ - that is, the closer we get to the small open economy case. Figure 5 illustrates the damping effect of the endogenous interest rate on debt. 
Comparing the two fertility scenarios, consumption is initially higher for the low fertility scenario, but not forever - until the year 2060 compared with 2057 for the closed economy. A welfare comparison of the two consumption paths reveals again that low fertility has a negligible impact. Again, low fertility yields a higher value of discounted consumption by $1.9 \%$.

\section{Optimal saving}

Here we synthesise the discussion of the responses of optimal saving under each of the three capital market assumptions and each of the two fertility scenarios. The paths are plotted in Figure 6. The first point is that in all scenarios population ageing results in temporary increase in saving followed by a decline to the new steady state level. This creates a short-term hump in saving. The initial increase in saving that forms the early part of the hump is due to initial capital deepening, or capital intensity effect, that temporarily raises income per effective worker. Consumption smoothing ensures that most of this temporary boost to income is saved and later consumed at the time when the process of capital deepening has unwound; at that time, therefore, saving falls.

For the closed economy and ICM models the initial rise in optimal saving is not as large as in the case of perfect capital mobility. This is due to effect of changes in the intertemporal terms of trade which are driven by the marginal product of capital in the closed economy and the interest rate in the ICM model. In the closed economy, as capital intensity rises the marginal product of capital, and hence the return to saving, falls which dampens the temporary rise in saving. In the ICM model the temporary rise in saving is dampened by a fall in the interest rate due to the fall in foreign liabilities as the saving 
rate rises. The simulations suggest that the more sensitive is the interest rate to changes in foreign liabilities the smaller the size of the temporary increase in optimal saving. Evidence for this is found in Figure 5 which shows the response of foreign liabilities to the slope in the interest rate equation, (10), which shows that higher values of this parameter imply smaller responses of foreign liabilities following the ageing shock. In this paper sensitivity of the interest rate to changes in foreign liabilities is interpreted as an indicator of the degree of capital mobility. In that case, the conclusion is that the increase in optimal saving in response to an ageing shock tends to be larger the greater the degree of capital mobility. In the extreme case of perfect capital mobility the return to saving is unaffected by the ageing shock, remaining equal to the world interest rate, which means there is no damping of the optimal saving response to the ageing shock.

\section{The effect of lower fertility on social welfare.}

Concerns about falling fertility rates in developed countries have led to calls for policies to boost the fertility rate. In Australia, for example, the federal government introduced a “baby bonus”. This is a cash payment of a minimum of $\$ 500$ per annum to the person with legal responsibility for a child born after 1 July 2001. The payment continues until the child is 5 years of age and the amount rises for higher income earners whose income has been reduced as a result of having responsibility for the child. Is this good public policy? One approach to this question is to consider what effect lower fertility rates have on social welfare. If the effect is negative, then policies such as the "baby bonus" in Australia can perhaps be defended as aiming to offset the effects of lower fertility on social welfare. 
For the closed economy and ICM models consumption under low fertility is higher for an initial period, but eventually falls below, consumption under base fertility. This raises the question of which consumption path is socially preferable - the low fertility or base fertility path. On the one hand such a question might be considered fundamentally unethical, because it implies making value judgements about the utility of future generations. However, economists do make intergenerational welfare comparisons using a discount rate. The effective discount rate implied in the models here is the sum of two components, representing the total cost to the central planner of delaying consumption. See equations (6) for the closed economy and (16) for the open economy. The first is the pure rate of time preference, $\theta$, that represents the central planner's aversion to a dollar of future consumption relative to a dollar of present consumption. The second component, $\beta g$, represents the central planner's rate of aversion to variability of consumption between time periods, $\beta$, times the rate of increase in potential consumption, $g$. The sum of the two components, $\theta+\beta g$, is equal to the marginal cost of an additional unit of capital.

However, whether this effective discount rate is the appropriate discount rate for very long planning horizons spanning many future generations is a moot point. This issue is discussed by Cline in Portney and Weyant eds. (1999). Cline makes the point (p.134) that the problem with using today's marginal product of capital to discount the very long future is that it implies a commitment by society that it cannot be relied upon to deliver. A commitment by society that a dollar of foregone consumption today will yield today's marginal product of capital for, say, the next 200 years is a commitment of dubious credibility according to Cline. He argues for a somewhat lower rate of discounting, one 
that "gives the distant future a fighting chance of being taken into account" (p.133). He prefers, for very long horizons, a rate of discounting equal to the reduction in the marginal utility of higher future consumption, $\beta g$. This would imply a zero rate of pure time preference which was argued by Ramsey, cited by Cline (p.132), to be more ethically defensible for intergenerational comparisons. ${ }^{7}$

A lower discount rate would imply a higher steady state capital stock in the closed economy model and a lower steady state level of debt in the open economy (see (6) and (16) respectively). This implies that the social planner's choice of discount rate amounts to a choice about the terminal steady state level of stocks - either capital stock or debt. If the planner believes that a high discount rate is unethical and therefore chooses a low discount rate, this is a simultaneous choice of high terminal capital stock or low terminal debt in a steady state. Moreover, it is also a choice about intergenerational transfers. A lower discount rate implies shifting consumption away from present generations to future generations and therefore bequeaths a lower debt or higher capital stock to future generations. A higher discount rate implies the opposite.

For the simulations reported in this paper, the discount rate is determined by first choosing $\beta=1.0$ and then setting the pure rate of time preference such that the steady state level of capital stock (closed economy) or debt (open economy) is equal to its initial level. This ensures that the capital stock or debt returns to its initial level following adjustment to the demographic shock. This resulting discount rate rate is $5.6 \%$ and $6.0 \%$ for the closed and open economies respectively. Table 1 reports the percentage gain in welfare from the low fertility scenario compared with the base scenario. The table also

\footnotetext{
${ }^{7}$ A pure rate of time preference arises from impatience.
} 
shows the same comparison for an alternative discount rate equal to $\beta g$ in both closed and open economy models. The latter discount rate implies a zero rate of pure time preference. For both discount rates the low fertility scenario generates slightly higher values of welfare under all three models: closed economy, ICM and small open economy models. Intermediate discount rates were found to give the same qualitative result. Subject to the important assumption that the fertility rate does not affect the rate of technical progress, the results suggest that low fertility is not likely to be welfarereducing.

\begin{tabular}{|l|c|c|}
\hline \multicolumn{2}{|c|}{ Table 1. \% gain in social welfare from low fertility. } \\
\hline & Base discount rate & Low discount rate \\
& & (zero pure time pref) \\
\hline Closed economy & $1.95 \%$ & $1.51 \%$ \\
\hline Imperfect capital mobility & $2.01 \%$ & $1.53 \%$ \\
\hline Small open economy & $2.48 \%$ & $2.07 \%$ \\
\hline
\end{tabular}

\section{Conclusion}

This paper was motivated by concerns about the adequacy of national saving rates and about the effect of low fertility rates in developed countries with ageing populations. These concerns have led to calls for policies to raise the rate of national saving, through tax increases for example, and to boost fertility rates, the "baby bonus" in Australia being one example cited. The focus of the analysis here is on the effect of capital mobility on 
the appropriateness of such policies. This follows prior work (Elemendorf and Sheiner, 2002) showing that the response of optimal saving to population ageing under perfect capital mobility and zero capital mobility (a closed economy) are qualitatively different. However, perfect and zero capital mobility are opposite extreme, almost hypothetical, cases. Given the empirical evidence that the capital markets of countries typically fall in between these two extremes, this paper considers the intermediate cases of imperfect capital mobility compared with the two extreme cases.

Two policy implications emerge from the analysis. First, there is a case for policies that encourage a modest boost to the national saving rate for countries that face imminent population ageing; and the size of the increase will tend to be larger for countries with higher capital mobility. In the extreme case of perfect capital mobility the return to saving is unaffected by the ageing shock. It remains equal to the world interest rate. With less than perfect capital mobility, however, the ageing shock lowers the return to saving, implying a lower increase in optimal saving.

The second implication of the analysis for policy is that a lower fertility rate confers a consumption dividend which allows an increase in social welfare for a plausible range of social discount rates. This result is unaffected, in a qualitative sense, by the degree of capital mobility and the quantitative estimates calculated here differ very little for alternative capital mobility assumptions. If lower fertility is not welfare-reducing as these results suggest, some other basis would have to be found for policies aimed at boosting fertility. 
Figure 1. The closed economy

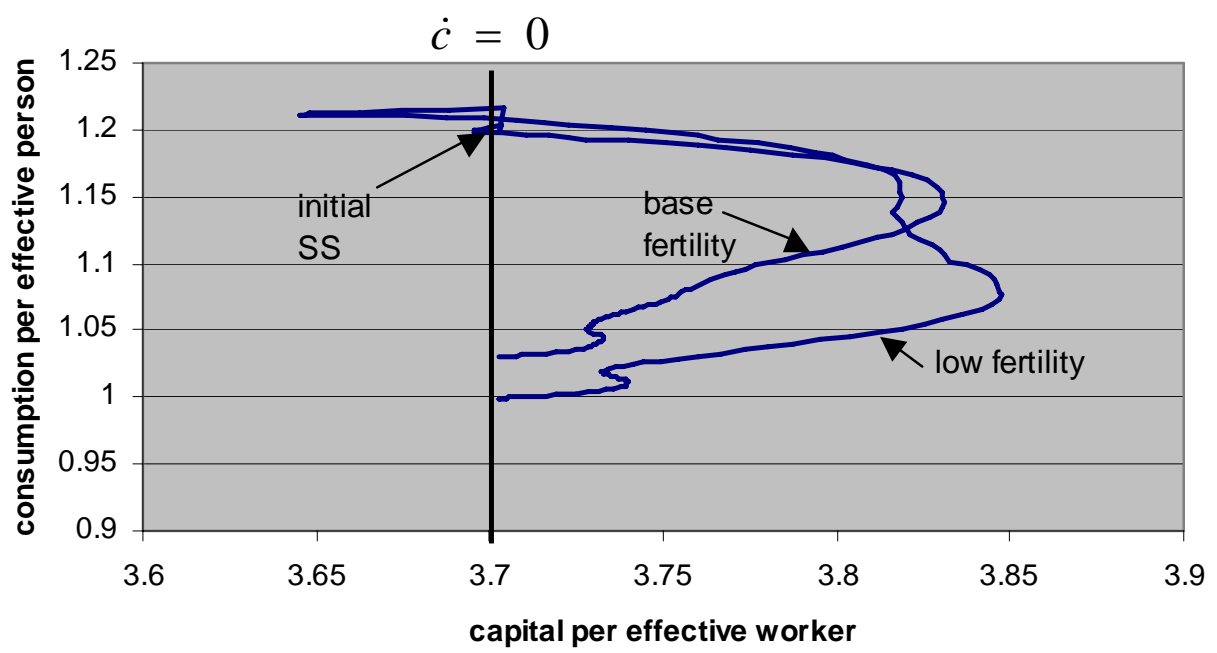

Figure 2. The small open economy

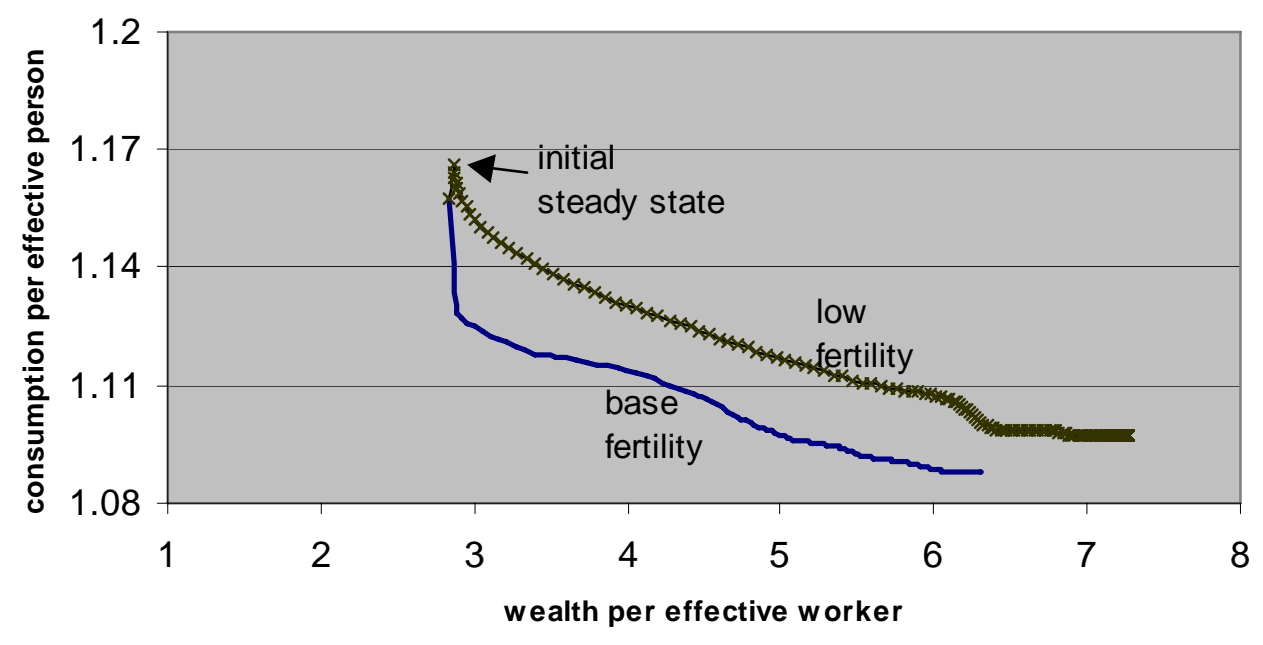

Figure 3. Imperfect capital mobility

$$
\lambda=0.02
$$

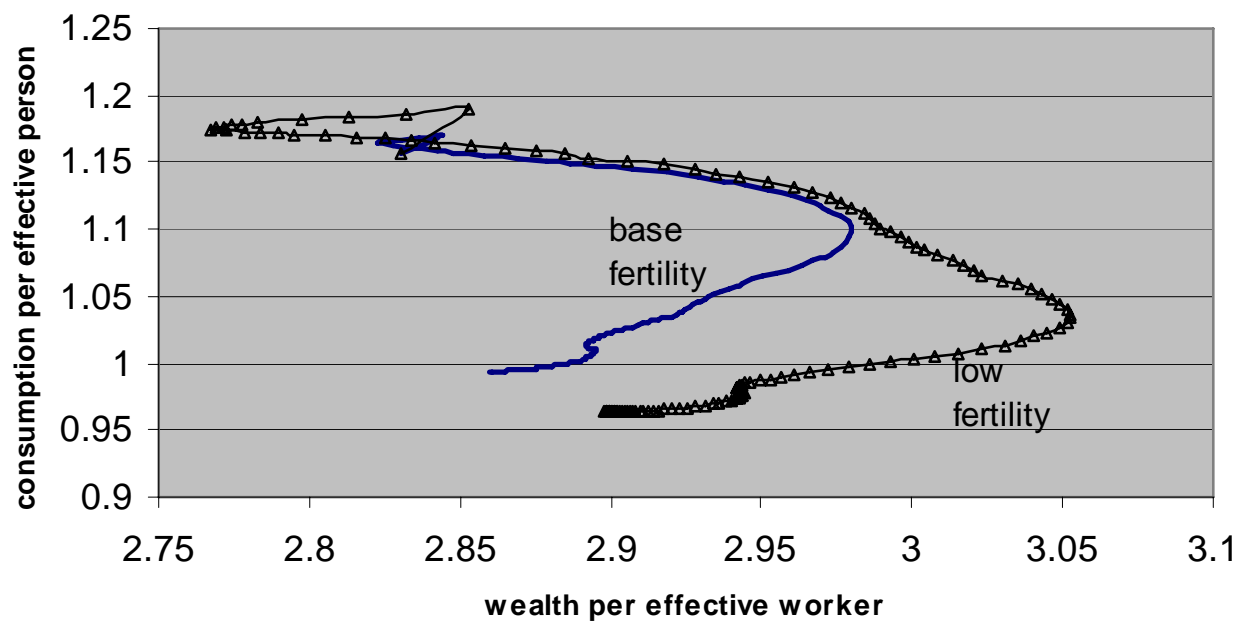



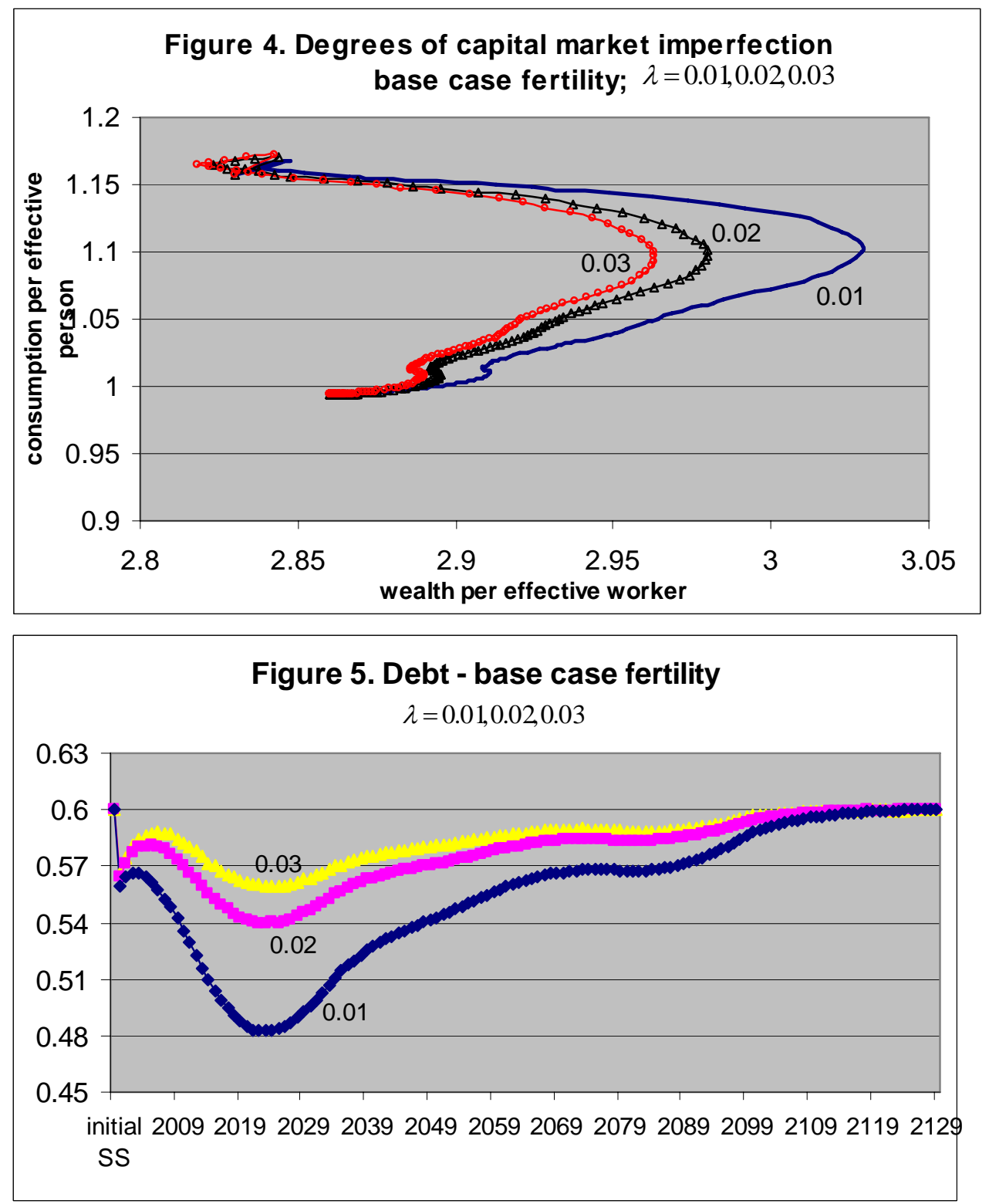

Figure 6. National saving rate (\% of GDP)

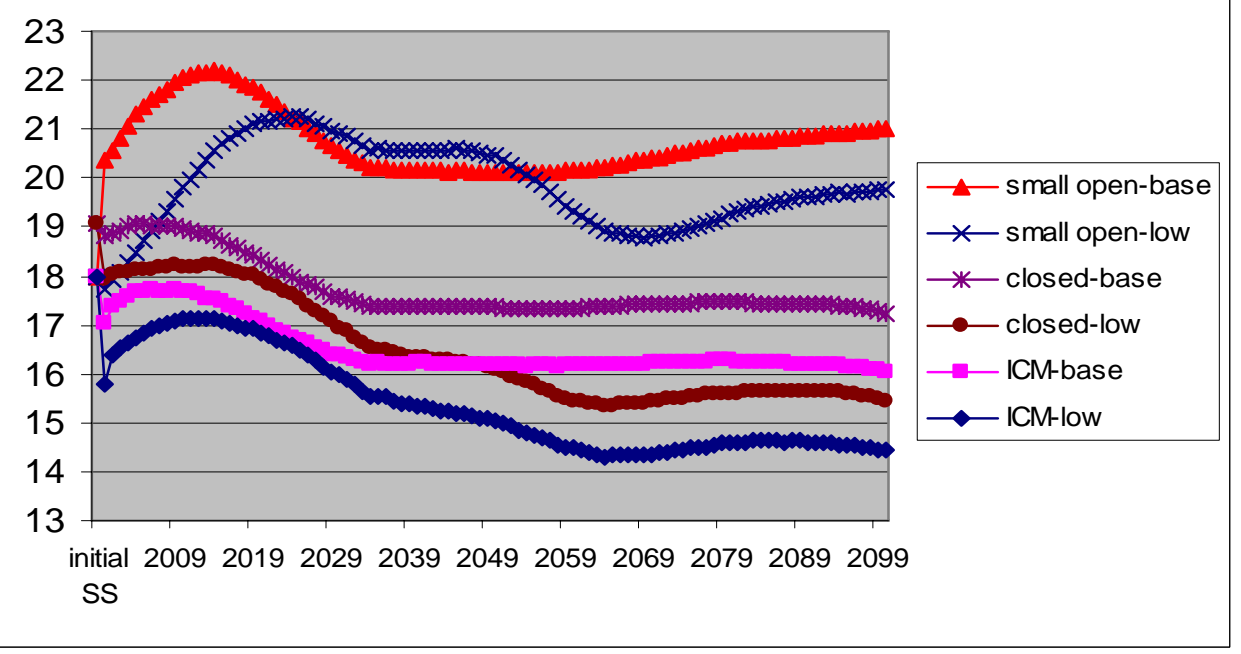




\section{References}

A.B.S. (1998), “Population Projections 1997 to 2051”, Australian Bureau of Statistics Catalogue 3222.0, Ausinfo, Canberra.

Ahituv, A. (2001), “Be Fruitful or Multiply: On the Interplay Between Fertility and Economic Development”, Journal of Population Economics, 14, 51-71.

Barro, R. and Sala-I-Martin, X. (1995), “Economic Growth”, McGraw-Hill, New York.

Benge, M. and Wells, G. (1998), “Growth in a Small Open Economy”, Working Paper No. 350, Department of Economics, Faculty of Economics and Commerce, Australian National University.

Coakley, J., Kulasi, F. and Smith, R. (1999), “The Feldstein-Horioka Puzzle and Capital Mobility: A Review”, International Journal of Finance and Economics, 3, 169188

Commonwealth of Australia (2002), “Intergenerational Report 2002-03”, Commonwealth of Australia, Canberra.

Cutler, D.M., Poterba, J.M., Sheiner, L.M. and Summers, L.H. (1990) "An Aging Society: Opportunity or Challenge?" Brookings Papers on Economic Activity, (1), pp.1-74.

Elmendorf, D.W. and Sheiner, L.M. (2000), “Should America Save for its Old Age? Fiscal Policy, Population Ageing and National Saving”, Journal of Economic Perspectives, 14, 3, 57-74.

Galor, O. and Hyoungsoo, Z. (1997), “Fertility, Income Distribution, and Economic Growth: Theory and Cross-Country Evidence”, Japan and the World Economy, 9, $197-229$ 
Glenn, K. (1997), “The Optimal Response of Consumption, Investment, and Debt Accumulation to an Exogenous Shock When the World Interest Rate is Exogenous”, Journal of Macroeconomics, 19, 2, 327-348

Gordon, R.H. and Bovenberg, A.L. (1996), "Why is Capital So Immobile Internationally? Possible Explanations and Implications for Capital Income Taxation”, American Economic Review, 86, 5, 1057-1075.

Guest, R.S. and McDonald, I.M., (2001) “Ageing, Optimal National Saving and Future Living Standards in Australia”, Economic Record, 77, 237, 117-134.

Guest, R. and McDonald, I.M., (2002), "Would a Decrease in Fertility be a Threat to Living Standards in Australia”, Australian Economic Review, 35, 1, 29-44

Hondroyiannis, G. and Papapetrou, E. (1999), “Fertility Choice and Economic Growth: Empirical Evidence from the U.S.”, I.A.E.R., 5, 1, 108-120.

Juttner, D.J. and Luedeckie, B.P. (1991), “Interest Rates, Exchange Rates and Foreign Debt”, The Economic Record, 67, 197, 139-146.

Portney, P.R. and Weyant, J. P. eds. (1999), “Discounting and Intergenerational Equity”, Resources for the Future, Washington D.C.

Steinman, G., Prskawetz, A. and Feichtinger, G. (1998), “A Model of Escape From the Malthusian Trap”, Journal of Population Economics, 11, 535-550 